\title{
Sex differences in athletes with asthma and exercise-induced bronchoconstriction: future directions
}

\author{
"Although the wider research community has realized the need to \\ focus on female participants/athletes, data are still scarce in relation \\ to asthma and athletes with e xercise-induced bronchoconstriction."
}

First draft submitted: 30 June 2017; Accepted for publication: 5 July 2017; Published online: 9 August 2017

Keywords: asthma $\bullet$ athletes $\bullet$ bronchoconstriction $\bullet$ exercise $\bullet$ gender $\bullet$ inflammation

- respiratory medicine

Exercise-induced bronchoconstriction (EIB) is a subtype of asthma with a prevalence of $90 \%$ in asthmatics and prevalences ranging from 10 to $50 \%$ in the elite athlete population [1-3]. Research indicates that asthma and/or EIB prevalence is high in male children and adolescents. In adults however, a switch occurs, with female rates dominating [4]. Adult females also report higher asthma exacerbations and hospitalizations [5]. Among athletes, females also outnumber their male counterparts with regards to presence of EIB, although the underlying mechanisms have not been elucidated $[3,6]$. This editorial aims to present the current state of the literature and signpost future directions of sex-based differences in athletic populations.

Particularly common in cold-weather athletes, EIB occurs due to repetitive breathing of dry air at high ventilation and exposure to environmental agents such as pollen, chlorinated compounds in swimming pools (in swimmers) and irritant agents from ice rinks.

The underlying mechanisms include an initial attempt of the airways to humidify the large volume of inspired air, causing evaporative water loss and a temperature drop at the airway surface, followed by development of a hyperosmolar environment. This in turn leads to the release of reactive mediators, such as histamine. In parallel to these cellular consequences, the cooling and quick rewarming of the airway surface induces a mechanical effect including edema and engorgement of the bronchial vasculature [7]. In an otherwise inflammatory environment, subsequent mucus overproduction, cough and presence of other typical asthma symptoms prevail, along with the worst and perhaps most critical symptom: airway narrowing [8].

Exercise has thus become a contradictory term for asthma researchers, in that it clearly improves cardiopulmonary fitness without much effect on lung function [9], and simultaneously lowers quality-of-life, particularly for highly trained athletes. Furthermore, it is evident from statistics highlighting asthma deaths in sports that white 10 - to 20 -year-old males with mild intermittent or persistent asthma are a particularly vulnerable group [10]. Asthma deaths occur in female subjects too, but to a lower extent. This could allude to female biology incurring a protective effect, although no theories have been proposed to support this. It is therefore more probable that higher prevalence rates linked to lower participation rates may be masking a potential increased risk for females participating in sports. This issue needs to be explored in more detail.

Perhaps, it is stating the obvious that there is a need to study male and female athletes and asthma/EIB association as so many

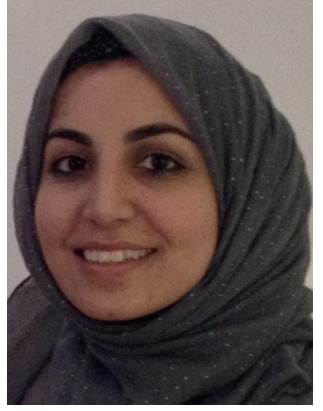

Nilam A Khan

Author for correspondence: School of Sport, Exercise \& Health Sciences, Loughborough University, Epinal Way, Loughborough, Leicestershire, LE11 3TU, UK

n.a.khan@lboro.ac.uk

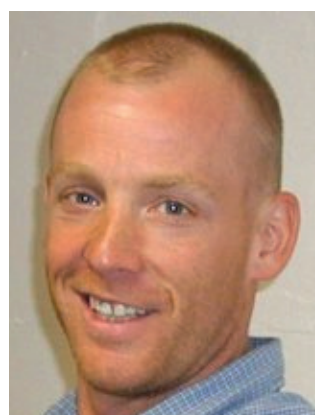

Martin R Lindley

School of Sport, Exercise \& Health Sciences, Loughborough University, Epinal Way, Loughborough, Leicestershire, LE11 3TU, UK

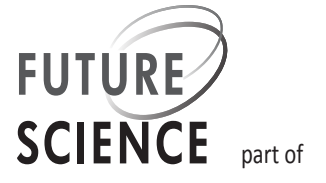


physiological changes (height, weight, etc.) occur with transition into adulthood, thus impacting lung function. In other chronic diseases, there is evidence of the importance of female biology. As an example, female hormones clearly play a role in risk association with cardiovascular disease while polycystic ovarian syndrome has been shown to serve as a predictor for both cardiovascular disease and diabetes [11]. Although the wider research community has realized the need to focus on female participants/athletes [12], data are still scarce in relation to asthma and athletes with EIB.

One noteworthy association has been proposed between EIB and the development of exercise-induced arterial hypoxemia in females. The bronchospasm occurring in EIB causes increase in airway resistance, which in turn has the potential to alter the ventilationperfusion ratio of the lung resulting in a drop of partial pressure of oxygen content in arteries. The study highlighting this association showed that $23 \%$ of female ice hockey players exhibited EIB and $76 \%$ also presented with exercise-induced arterial hypoxemia, at their maximal level of exercise intensity [13]. Studies such as these are promising as the information arising from these will eventually allow for biological mechanisms to be explained in detail.

\section{"...there is no consensus within the literature that fully elucidates the underpinning mechanisms of sex-based differences in exercise-induced, bronchoconstriction prevalence and severity."}

Furthermore, the menstrual cycle has been shown to exert notable effects in female athletes. A study conducted on female athletes [14] encompassing the expression of over a 100 inflammatory genes after aerobic exercise, highlight a marked proinflammatory gene upregulation during the follicular phase (menstrual cycle day 10) of these women accompanied by an anti-inflammatory gene downregulation during their luteal phase (day 25), in comparison with a group of male subjects serving as controls. However, the subsequent protein expression profile associated with these findings at gene level is not yet fully elucidated.

Moreover, estrogen is thought to exhibit both proand anti-inflammatory effects, mostly demonstrated by in vitro findings. Notably, estrogen receptors are thought to be expressed on both smooth muscle and vascular endothelial cells, thus suggesting a possible link between hormonal regulation and development of asthma and airway hyper-responsiveness/EIB [15].

Lung function and EIB symptoms are also significantly worse in female athletes during mid-luteal phase when salivary progesterone levels are at peak, compared with mid-follicular menstrual cycle phase when salivary progesterone levels are lower [16].
There are several challenges posed when including female participants in research studies, including the need to conform to menstrual cycle changes over the course of the month encompassing intersubject differences in fertility phase: menopausal age and absence of puberty (children), and of course the absence or disruption of menstrual cycle in female athletes along with the use of oral contraceptives. All these factors are known to influence immunological and physiological functions in females. These challenges may be overcome by designing small cohorts, as studies on athletes typically involve low number of participants. Northoff's study on gene expression involved 9 females and 12 males: a relatively small cohort compared with other gene expression studies. Some researchers may disagree with this [12], and instead suggest studies involving female subjects should be larger in order to account for intersubject differences in hormone profiles and to provide sufficient study power.

To conclude, there is increasing evidence of female athletes exhibiting more severe EIB/asthma, particularly during the latter part of their menstrual cycle. To date however, there is no consensus within the literature that fully elucidates the underpinning mechanisms of sex-based differences in EIB prevalence and severity. To some extent, there is also limited acceptance that this issue needs to be interrogated further. The future may allow for females to gain greater control of their respiratory health through knowledge of their hormones and their effects thereof. This knowledge has further potential to expand into the wider research community, thus allowing athletic professionals to study performance effects and medical researchers to develop novel therapeutic targets based on male and female biology and their respective differences. The time is therefore now to call for more research into this fascinating subject area.

\section{Financial \& competing interests disclosure}

The authors have no relevant affiliations or financial involvement with any organization or entity with a financial interest in or financial conflict with the subject matter or materials discussed in the manuscript. This includes employment, consultancies, honoraria, stock ownership or options, expert testimony, grants or patents received or pending, or royalties.

No writing assistance was utilized in the production of this manuscript.

\section{Ethical conduct of research}

The authors state that they have obtained appropriate institutional review board approval or have followed the principles outlined in the Declaration of Helsinki for all human or animal experimental investigations. In addition, for investigations involving human subjects, informed consent has been obtained from the participants involved. 
Open access

This work is licensed under the Creative Commons Attribution
4.0 License. To view a copy of this license, visit http://creativecommons.org/licenses/by/4.0/

9 Chandratilleke MG, Carson KV, Picot J, Brinn MP, Esterman AJ, Smith BJ. Physical training for asthma. Cochrane Database Syst. Rev. 5, CD001116 (2012).

10 Becker JM, Rogers J, Rossini G, Mirchandani H, D’ Alonzo GE, Jr. Asthma deaths during sports: report of a 7-year experience. J. Allergy Clin. Immunol. 113, 264-267 (2004).

11 Franks S, White DM. Prevalence of and etiological factors in polycystic ovarian syndrome. Ann. NY Acad. Sci. 687, 112-114 (1993).

12 Macsali F, Svanes C, Bjorge L, Omenaas ER, Gomez Real F. Respiratory health in women: from menarche to menopause. Expert Rev. Respir. Med. 6, 187-200; quiz 201-2 (2012).

13 Game A, Voaklander D, Syrotuik D, Bell G. Incidence of exercise-induced bronchospasm and exercise-induced hypoxaemia in female varsity hockey players. Res. Sports Med. 11, 11-21 (2003).

14 Northoff H, Symons S, Zieker D et al. Gender- and menstrual phase dependent regulation of inflammatory gene expression in response to aerobic exercise. Exerc. Immunol. Rev. 14, 86-103 (2008).

15 de Oliveira AP, Domingos HV, Cavriani G et al. Cellular recruitment and cytokine generation in a rat model of allergic lung inflammation are differentially modulated by progesterone and estradiol. Am. J. Physiol. Cell Physiol. 293, C1120-C1128 (2008).

16 Stanford KI, Mickleborough TD, Ray S, Lindley MR, Koceja DM, Stager JM. Influence of menstrual cycle phase on pulmonary function in asthmatic athletes. Eur. J. Appl. Physiol. 96, 703-710 (2006). 